\title{
Acute aphakic pupil block glaucoma: an alternative surgical approach
}

\author{
R. A. HITCHINGS
}

From the Department of Clinical Ophthalmology, Moorfields Eye Hospital, London

SUMMARY In a series of 7 cases of acute aphakic pupil block glaucoma a surgical approach designed to break adhesions between the iris and the anterior hyaloid face was uniformly successful. Reasons for the success of the method are discussed and comparisons made with other surgical approaches.

Acute aphakic pupil block glaucoma is a relatively uncommon condition characterised by ocular hypertension, shallowing of the anterior chamber, and marked anterior convexity of the iris together with angle closure (Figs. 1 and 2). It can develop at any time in the first few weeks after cataract extraction. The hyaloid face may be intact, protruding into the anterior chamber, and, less frequently nowadays, broken and prolapsing through a posterior capsu-

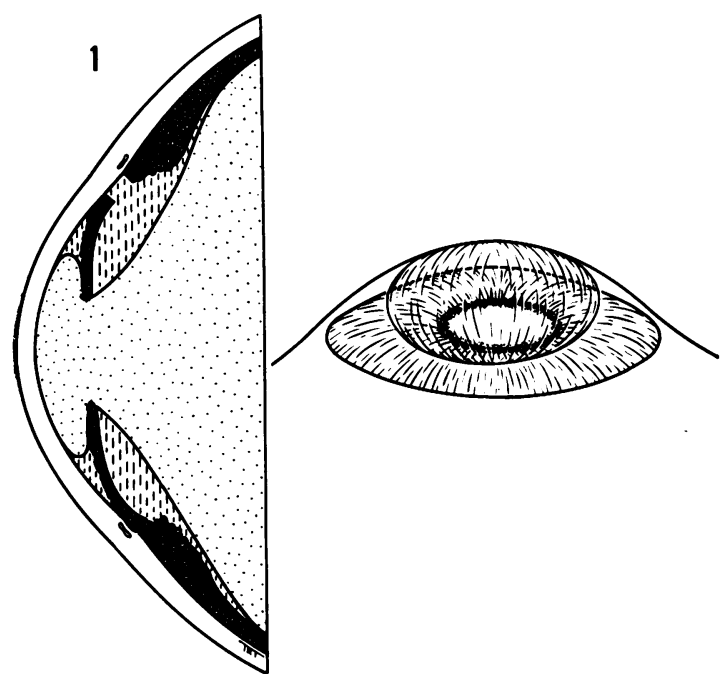

Fig. 1 Cross-section and diagrammatic three-dimensional view indicating relationships between vitreous, aqueous, and iris in aphakic pupil block. It should be noted that the plan of iridovitreal contact drawn is only one of the three theoretical possibilities (see text)

Address for reprints: Mr R. A. Hitchings, King's College Hospital, Denmark Hill, London SE5 8RX

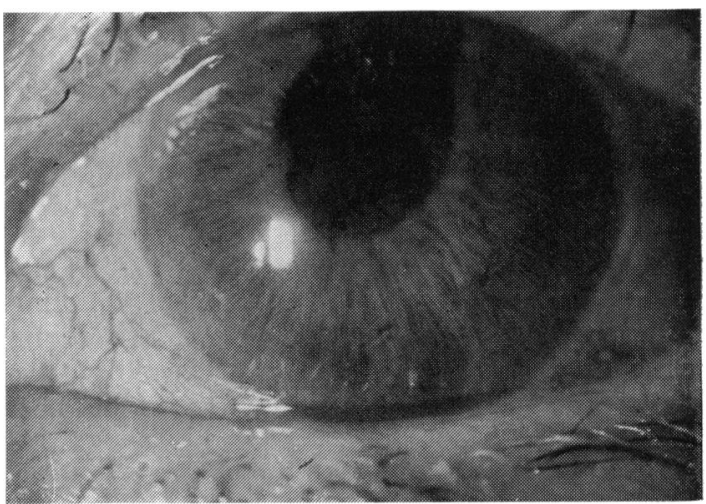

$2 a$

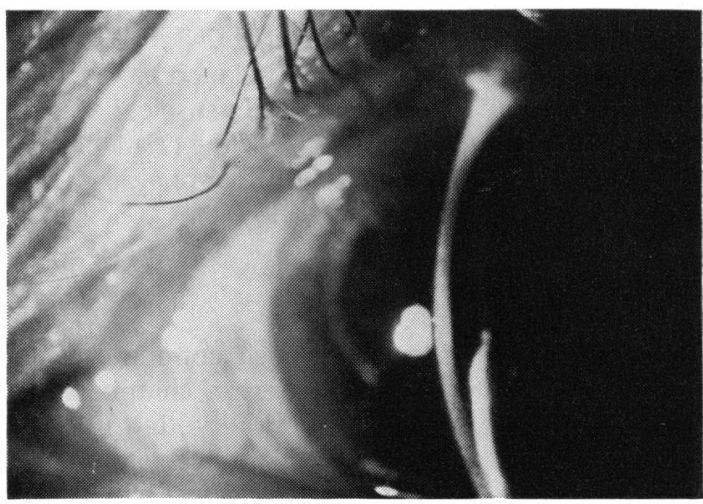

$2 \mathrm{~b}$

Figs. 2a and b Diffuse and slit illumination of an eye of Patient 4 with aphakic pupil block

lotomy. In both instances, vitreoendothelial contact is the rule, the glaucoma being complicated by corneal endothelial decompensation. Recognition of the condition prompts immediate treatment with 
mydriatics, carbonic anhydrase inhibitors, and hyperosmotic agents in an attempt to break the pupil block. Mydriasis may not be achieved if the intraocular pressure is too high or the anterior chamber flat. Even if mydriasis is achieved in those eyes with an intact anterior hyaloid, iridovitreal adhesion may persist with tightening the anterior hyaloid, so that despite deepening of the anterior chamber the pupil block persists.

Failure to obtain rapid cure with medical treatment is an indication for surgical intervention in the hope of preventing both irreversible damage to the optic nerve as well as chronic aphakic angle closure glaucoma. This paper is concerned with the surgical cure of aphakic pupil block in eyes with an intact anterior hyaloid and will describe an alternative surgical approach to those techniques promulgated at present.

Many surgical techniques have been described for relieving this condition. They can be divided into operations based on (a) the concept of aqueous pooling behind the iris and in front of the anterior hyaloid, the operations including iridotomy (Bowman, 1863), needling (Smith, 1891), iridectomy (Knapp, 1895; Weeks, 1923; and others), and argon laser iridotomy (Anderson et al., 1975; Patti and Cinotti, 1975); and (b) the concept of intraor retrovitreal pooling of aqueous, the operations including incision of the anterior hyaloid face (Shaffer, 1954; Wright, 1968) and vitreous aspiration with and without iridectomy (Shaffer, 1954; Chandler, 1954; Meisekothen and Allen, 1968; and others). The very multiplicity of surgical approaches suggests that none is ideal. This paper describes a simple surgical approach, found to be effective in 7 successive cases of aphakic pupil block glaucoma. Simplicity together with a successful surgical result suggests that this technique should be tried first in the surgical treatment of acute aphakic pupil block.

\section{Operative technique}

The operation aims to re-establish communication between the posterior and anterior chambers by separating iris from anterior hyaloid with a Castroviejo iris repositor (chosen because the long narrow blade facilitates delicate manipulations within the anterior chamber).

Under local or general anaesthesia the eye is fixed at the limbus by means of fine-toothed forceps. A transcorneal paracentesis just anterior to the site of fixation is performed with a Bowman knife. As the anterior chamber is, at best, extremely shallow, the knife track has to be a very shelving one.

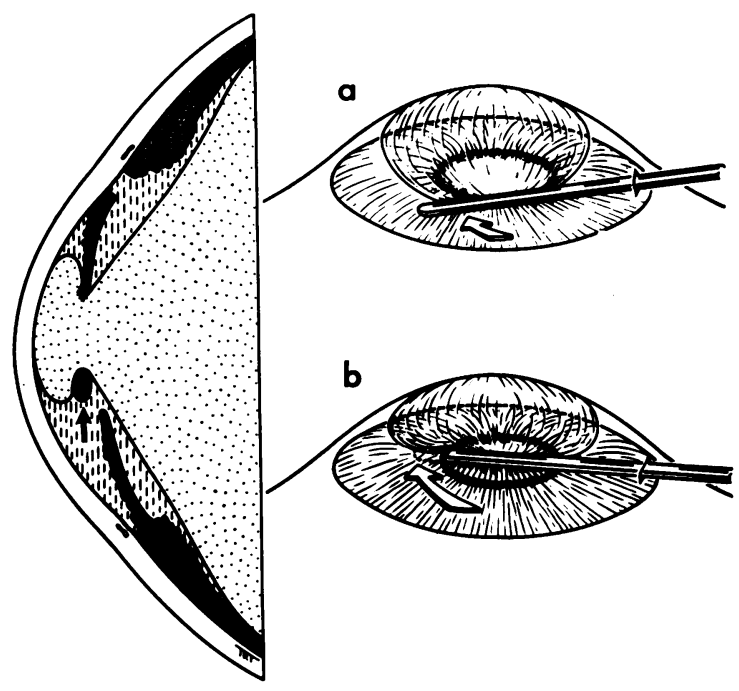

Fig. 3 Cross-section and diagrammatic three-dimensional view illustrating the 'sweep' action of the iris repositor. In the cross-section the repositor is shown breaking the pupil block by stretching anterior hyaloid face, (black arrow). In the three-dimensional views the iris repositor (white arrow) is shown lying in front (a), and behind (b) the iris plane while separating iris from anterior hyaloid

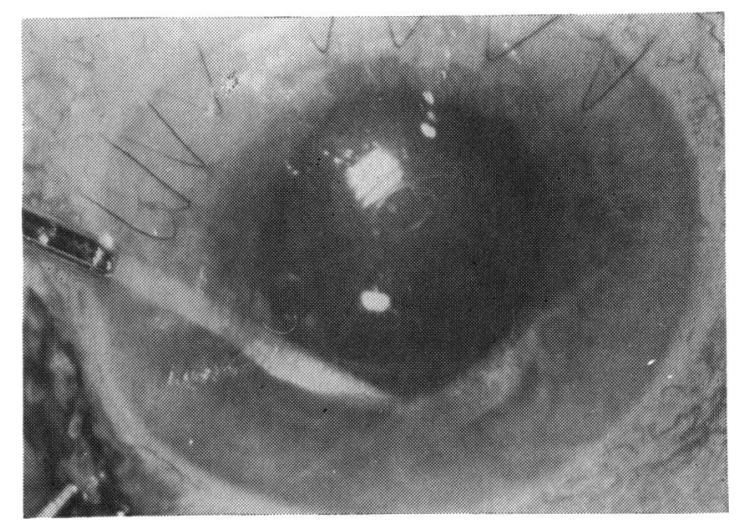

Fig. 4 Photograph showing iris repositor passing behind the iris

The Castroviejo repositor is introduced into the anterior chamber, gently displacing the convex iris surface posteriorly so as to avoid contact with the corneal endothelium. The repositor is directed above or, more usually, below the pupil margin so as to lie between the anterior iris surface and the protruding vitreous face (Figs. 3 and 4). Care must be taken not to perforate the anterior vitreous face with the blunt end of the repositor. Sufficient length of the repositor is introduced into the anterior chamber to enable the tip to reach that part of the 

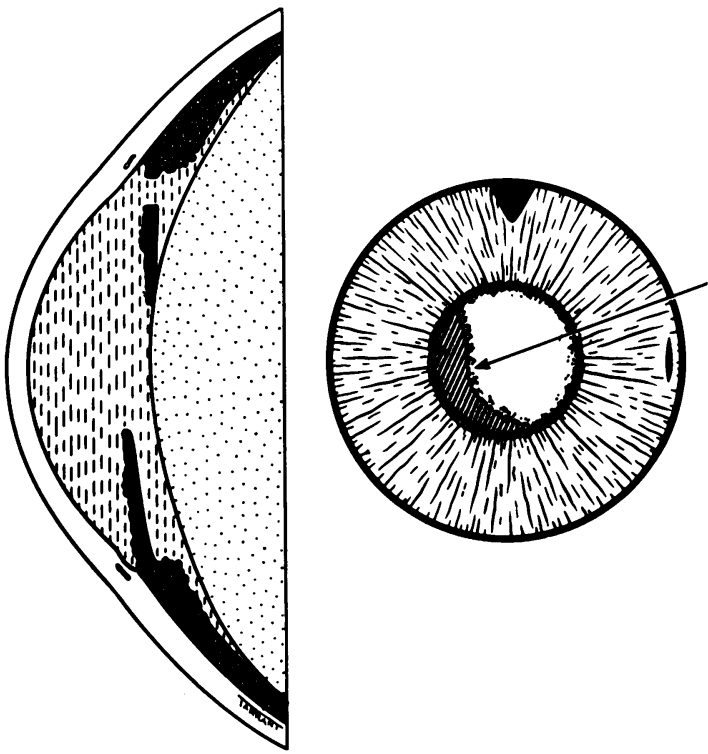

Fig. 5 Diagrammatic cross-section and external view after successfully treating aphakic pupil block. The cross-sectional diagram shows a deep anterior chamber having free communication with the posterior chamber. The external view demonstrates the occasional line of pigment on the anterior hyaloid surface indicating the line of iridovitreal adhesion (arrow)

pupil farthest away from the paracentesis site. The shaft of the repositor is swept towards the pupil, pushing the anterior hyaloid face before it. This action stretches the anterior hyaloid and in some cases is sufficient to slide the vitreous face from behind the iris, breaking any iridovitreal adhesions.

Immediate deepening of the anterior chamber indicates that communication between anterior and posterior chambers has been re-established. Whether or not the anterior chamber has deepened, the tip of the repositor is introduced through the pupil close to the pupil margin and passed between iris and anterior hyaloid. The repositor may now be swept along the pupil margin for close to $180^{\circ}$ separating the iris from the anterior hyaloid face. In the 7 cases reported here these 2 manoeuvres successfully broke the pupil block, shown in each case by spontaneous deepening of the anterior chamber (Figs. 5 and 6). It should be emphasised that, although the pupil block has been broken, the subsequent intraocular pressure depends on the extent to which the angle of the anterior chamber was occluded or damaged before the operation.

Three eyes in this series had developed iris prolapse by the time they were operated upon. In each case it was possible to 'hook' the repositor through

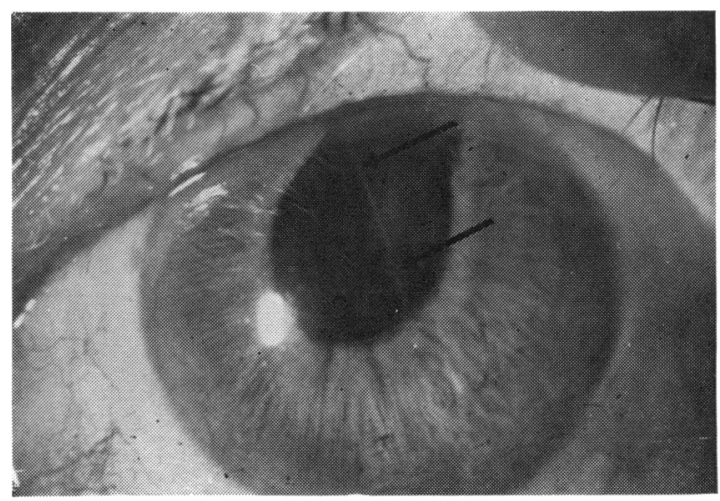

$6 a$

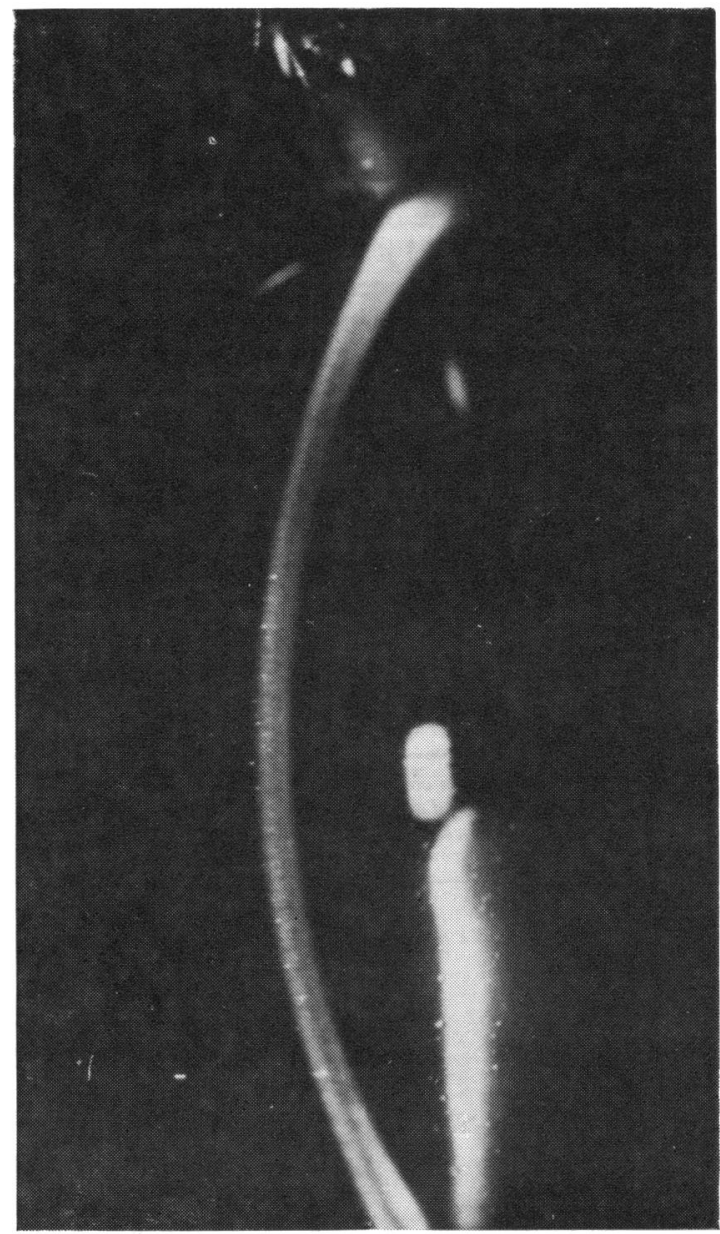

$6 \mathrm{~b}$

Figs. 6a and b Photographs of Patient 4 after successfully breaking the pupil block illustrating the deep anterior chamber together with a pigmented line on the anterior hyaloid face (arrow) 


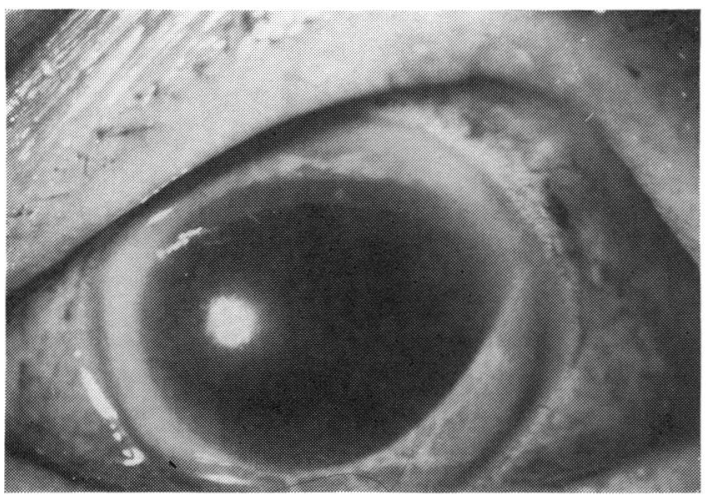

$7 a$

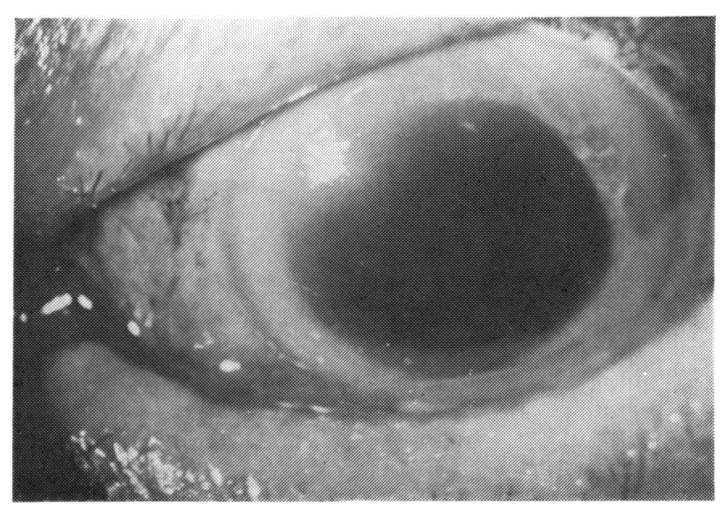

7b

Figs. 7a and b Photographs of Patient 3 before operation with an iris prolapse, and postoperatively after the iris had been pulled back into the anterior chamber

the iridectomy and pull the iris away from and out of the section. No repair of the section was required (Fig. 7). In the other eyes after the anterior chamber had deepened it became apparent that the vitreous face was still occluding the iridectomy. It was possible to pass the iris repositor through the iridectomy and stretch the aperture sufficiently to break the iridovitreal adhesion.

\section{Results}

These have been summarised in Table 1. Patients 1 and 2 each had an unsuccessful incision of the anterior hyaloid face and anterior vitreous before the iridovitreal adhesions were divided. Patient 3 had persistent ocular hypertension despite a deep anterior chamber and required a further operation for glaucoma within the first month. No eye suffered visible corneal endothelial decompensation with corneal oedema. In Patients 1 and 2 the incised anterior hyaloid face reformed, and at 1 month only 1 eye had a persistently broken anterior vitreous face. In a number of eyes a line of pigment on the anterior hyaloid face indicated a line of pupillovitreal adhesions (Figs. 5 and 6).

\section{Discussion}

It is convenient to divide the discussion into 3 sections: the location of retroiridic aqueous, the

Table 1 Aphakic pupil block-results

\begin{tabular}{|c|c|c|c|c|c|c|}
\hline \multirow[b]{2}{*}{ Patient } & \multirow{2}{*}{$\begin{array}{l}\text { Time between cataract } \\
\text { extraction and diagnosis } \\
\text { of pupil block }\end{array}$} & \multirow[b]{2}{*}{$I O P$} & \multirow[b]{2}{*}{ Surgical approach } & \multicolumn{3}{|c|}{ One month post operation for aphakic pupil block } \\
\hline & & & & $I O P$ & $\begin{array}{l}\text { Anterior hyaloid } \\
\text { face }\end{array}$ & $\begin{array}{l}\text { Anterior chamber } \\
\text { depth }\end{array}$ \\
\hline 1 & 1 week & 45 & $\begin{array}{l}\text { Incision anterior hyaloid then } \\
\text { division posterior synechiae. } \\
\text { Repositor used to pull iris out of } \\
\text { section }\end{array}$ & 18 & Intact & Deep \\
\hline 2 & 2 weeks & 40 & $\begin{array}{l}\text { Incision of anterior hyaloid first, } \\
\text { then division posterior synechiae }\end{array}$ & 15 & Intact & Deep \\
\hline 3 & 1 day & 35 & $\begin{array}{l}\text { Division posterior synechiae. } \\
\text { Repositor used to pull iris from } \\
\text { section }\end{array}$ & $14^{*}$ & Intact & Deep \\
\hline 4 & 1 week & 30 & Division posterior synechiae & 21 & Intact & Deep \\
\hline 5 & 2 days & 42 & Division posterior synechiae & 18 & Intact & Deep \\
\hline 6 & 2 days & 35 & Division posterior synechiae & 15 & Intact & Deep \\
\hline 7 & 2 days & 45 & $\begin{array}{l}\text { Division posterior synechiae with } \\
\text { rupture anterior hyaloid }\end{array}$ & 10 & Broken & Deep \\
\hline
\end{tabular}

* Further glaucoma surgery was required 3 days later despite cure of the pupil block because of residual peripheral anterior synechiae 
surgical technique, and possible retro- and intravitreal pooling of aqueous.

LOCATION OF RETROIRIDIC AQUEOUS

The iris may have aqueous, aqueous and vitreous gel, and solely vitreous gel in contact with the posterior iris surface (Shaffer, 1954; Chandler, 1954; Weiss and Shaffer, 1972; Anderson et al., 1975). In the first instance pupillovitreal adhesions, in the absence of a patent iridectomy, are the cause of the block. Examples of this have been demonstrated on histological sections by Smith (1891), Hudson (1912), Shaffer (1954), and others. These eyes may or may not have extensive inflammatory exudate within the anterior chamber (Chandler and Johnson, 1947).

Adhesions between the posterior iris surface and the anterior hyaloid face have been cited as reason for the failure of an iridectomy (Kolker and Hetherington, 1976) or laser iridotomy (Anderson et al., 1975) to break the block at one site but not at another.

If it were possible to identify those parts of the iris with aqueous behind them, iridectomy would be a reasonable and certainly curative procedure. Kolker and Hetherington (1976) note, however, that iridectomy under these conditions is a 'formidable' procedure, and certainly the thought of performing an iridectomy in a hypertensive aphakic eye in which vitreous may lie immediately behind the iris is not obviously attractive. Kolker and Hetherington (1976) suggest looking through the pupil for an 'optically clear zone' within the anterior vitreous that may be a pocket of aqueous, and performing an iridectomy at that site. In the author's experience, however, persistent corneal stromal oedema in many eyes prevented a sufficiently clear view of the anterior vitreous to observe such optically clear zones.

Ultrasound scanning might show an interface between aqueous pool and the retrodisplaced anterior hyaloid. B-scan ultrasound was performed for 2 of the eyes, but such an interface could not be seen. In 1 eye not reported here, which had aphakic pupil block for at least 2 months, an acoustically clear zone behind the iris could be seen (McLeod, personal communication). Failure to visualise such acoustically clear zones in 2 eyes reported here only reflected the ultrasound being obtained soon after onset of the block, when the aqueous pool is presumably much smaller. Buschman and Linnert (1976), however, reported echo-free areas within the vitreous cavity in eyes with aphakic pupil block and suggested that these regions were pockets of aqueous. But differentiation by ultrasound between intravitreal aqueous and areas of vitreous gel collapse may well be impossible.
There would not appear to be a certain method of establishing whether aqueous or vitreous is behind any part of the iris. The problem of where to place the iridectomy was overcome by Anderson et al. (1975), who noted that if one (full thickness) laser iridotomy failed to break the block a second (and presumably a third) site could be chosen. Anderson et al. noted, however, that dark coloured irides required much more energy to produce an iridotomy, and that they could not produce one in every eye to be treated. The energy required to obtain an iridotomy with the argon laser might result in damage to other intraocular structures (Wheeler, 1977). The dye laser delivers less energy while producing an iridotomy, and so might perhaps be an ideal treatment for this condition (Perkins, personal communication).

A major advantage of retroiridic sweeping with a Castroviejo spatula is that at least $120^{\circ}$ of the iris may be treated, and by breaking down possible iridovitreal adhesions over this area the operation has a far greater chance of establishing communication between the anterior and posterior chambers than an iridectomy or an iridotomy.

\section{SURGICAL TECHNIQUE}

This method of dividing pupillovitreal adhesions is not new, being first suggested to the author by P. Spaeth (personal communication). Christensen (1967) suggested another method of breaking the pupil block when he noted the success of passing an iris repositor through an iridectomy, behind the iris and then through the pupil, to break pupillovitreal adhesions in eyes with excessive inflammatory exudate in the anterior chamber.

The major advantages of this technique are speed and simplicity. No special precautions need be taken. The preoperative intraocular pressure should be low enough for the cornea to remain clear. In fact an intraocular pressure greater than $21 \mathrm{mmHg}$ facilitates paracentesis.

The shallow anterior chamber requires a very shelving paracentesis track. The shelving nature of the track ensures that it acts as a valve, collapsing to prevent iris prolapse when the knife is withdrawn before inserting the iris repositor.

It is essential to be able to delineate the extent of the protruding vitreous face so that the Castroviejo repositor is positioned between the vitreous face and the iris surface. Care has to be taken not to push the iris repositor through the anterior hyaloid face before passing it behind the pupil. Should this occur, it is difficult to exert traction on the anterior hyaloid face and break the posterior synechiae. Furthermore when the tip of the spatula is pushed behind the iris it will remain within the vitreous gel 
and fail to establish a communication between the posterior and anterior chambers.

In those eyes in which sweeping the anterior hyaloid face is sufficient to break pupillovitreal adhesions, and thus break the pupil block, the vitreous face retracts and the anterior chamber deepens. Under these conditions the operator can be reasonably sure that the iris repositor passes between the pupil margin and the anterior hyaloid face. When this initial manoeuvre is insufficient, the operator cannot be sure that the iris repositor does not perforate the anterior hyaloid. (If it does, to cure the block the repositor must reperforate the face to gain entry into the aqueous pool formed around the ciliary processes. Unless this occurs, the aqueous cannot gain entry into the anterior chamber and the vitreous gel will not retract.)

The appearance of the vitreous face after cure of the pupil block allows differentiation between transfixing the vitreous gel and dividing the posterior synechiae. In the former condition aqueous will gain entry into the anterior chamber through the broken vitreous face, the break will remain, and, commonly, vitreous 'tags' will float into the anterior chamber, indicating the forward flow of aqueous. With division of posterior synechiae the vitreous face remains intact.

In this series the vitreous face was formed the day after operation in all but 1 eye, suggesting that aqueous drained into the anterior chamber around and not through the vitreous gel, and that cure of the pupil block followed division of posterior synechiae.

A sudden deepening of the anterior chamber indicated successful re-establishing of communication between anterior and posterior chamber. This useful end point removes the need for deepening of the anterior chamber with either air or saline-but see Jones (1968), Kolker and Hetherington (1976), and Jaffe (1976). The reason for the sudden reformation of the chamber is not clear. What may happen is that vitreous gel 'plugs' the pupil (and any iridectomy), and then as aqueous leaves the anterior chamber the gel is pushed forward by aqueous trapped in the posterior chamber. The gel structure remains attached at the vitreous base, however, and when the iris repositor deforms the plug its size is reduced so that the stretched collagen fibrils within the vitreous gel regain their normal length by retracting into the posterior segment. The dilator muscle of the iris is stretched by the bowing forwards of the iris into the anterior chamber. When the vitreous plug retracts, the iris dilator muscle contracts, removing the anterior convexity. Aqueous flows forward passively to fill the space created between iris and cornea, thus reforming the anterior chamber.
As soon as the anterior chamber does deepen, the iris repositor may be withdrawn. No corneal sutures are necessary. Topical steroid and cycloplegics are instilled.

Two of the eyes in this series suffered partial iris prolapse secondary to wound dehiscence under high pressure. In some eyes (not reported here) failure to diagnose aphakic pupil block has in the author's experience caused sufficient of the iris to prolapse to break the block, causing spontaneous deepening of the anterior chamber. For the 2 eyes in this series with iris prolapse, after the block had been broken the iris repositor was hooked around an adjacent iridectomy and used to pull the iris back into the eye. In each case, the wound was considered adequately sutured and no further action to repair it was required.

The pupil block has not been broken until the anterior chamber deepens. If retroiridic sweeping fails to break the block, it would be reasonable to diagnose 'ciliovitreal block' (Weiss and Shaffer, 1972) and search for intra- or retrovitreal aqueous.

\section{NTRA - AND RETROVITREAL POOLING OF AQUEOUS}

The concept of aqueous migrating posteriorly into the vitreous gel and eventually into the retrohyaloid space arose from $(a)$ the occasional failure of an iridectomy to cure the condition, and $(b)$ the success of incising the anterior hyaloid face in eyes with aphakic pupil block.

Incision of the anterior hyaloid face is not entirely satisfactory. It was recommended by Chandler and Johnson (1947) to remove obstruction to aqueous flow caused by an inflammatory membrane occluding the pupil. Shaffer (1954) suggested incision of the anterior hyaloid face even without an obvious inflammatory membrane, noting, however, that simple incision was not always enough to break the pupil block. Similar doubts about the efficacy of incising the anterior hyaloid face were expressed by Kolker and Hetherington (1976) and Jaffe (1976), all 4 authors recommending aspiration of retrovitreal aqueous.

One reason for the failures seen with incising the anterior hyaloid face was evident in Patients 1 and 2 in this series. In both cases initial incision failed to break the pupil block, which was, however, broken by retroiridic sweeping. An important point is that the anterior hyaloid face subsequently reformed, this suggesting that retroiridic pooling of aqueous, only, had occurred. This preferential location for the aqueous pool would explain failures seen with incision of the hyaloid face, for unless the block had been present for a long time, with collection of a large volume of aqueous, the 
essentially posteriorly directed stroke of the instrument used to incise the face would not enter the aqueous pool.

\section{Conclusion}

The eyes with aphakic pupil block glaucoma presented in this paper were cured on re-establishing communication between the posterior and anterior chambers by retroiridic 'sweeping' with a Castroviejo iris repositor. The ease and simplicity of the manoeuvre suggest that it should be tried first in all cases of aphakic pupil block when retroiridic pooling of aqueous is suspected.

The author thanks surgeons at Moorfields Eye Hospital for referring cases under their care, Mr Redmond Smith for helpful discussion, $\mathrm{Mr} \mathrm{T}$. Tarrant for the diagrams, and Miss D. Martin for typing the manuscript.

\section{References}

Anderson, D. R., Forster, R. K., and Lewis, M. L. (1975). Laser iridotomy for aphakic pupillary block. Archives of Ophthalmology, 93, 343-346.

Bowman, W. (1863). An extraction of cataract by a traction instrument, with iridectomy: with the remains of capsular obstructions and their treatment. Ophthalmic Hospital Reports, 4, 332-363.

Buschman, N. W., and Linnert, D. (1976). Glaskor Perechographie bei Aphakie und malignem Aphakie Glaucom. Klinische Monatsblätter für Augenheilkunde, 168, 453-461.

Chandler, P. A. (1954). In discussion. Transactions of the American Academy of Ophthalmology and Otolaryngology, 58, 229-231.

Chandler, P. A., and Johnson, C. C. (1947). A neglected cause of secondary glaucoma in eyes in which the lens is absent and subdued. Archives of Ophthalmology, 37, 740-771.

Christensen, L. (1967). Post-operative shallowing of the anterior chamber. American Journal of Ophthalmology, 64, 600-606.

Hudson, A. C. (1912). Injury to the vitreous as a factor in the production of secondary glaucoma. Ophthalmic Hospital Reports, 18, 203-223.

Jaffe, N. S. (1976). Cataract Surgery and its Complications, 2nd edn., p. 231. Mosby: St. Louis.

Jones, B. R. (1968). In discussion. Transactions of the Ophthalmological Societies of the United Kingdom, 78, 471-475.

Knapp, H. (1895). Ueber Glaucom nach Discussion des Nachstaars und seine Heilung. Archiv für Augenheilkunde, 30, 1-36.

Kolker, A. E., and Hetherington, J. (1976). Becker-Shaffer's Diagnosis and Therapy of the Glaucomas, 4th edn., p. 204. Mosby: St. Louis.

Meisekothen, W. E., and Allen, J. C. (1968). Treatment of pupillary block caused by aqueous pooling in vitreous. American Journal of Ophthalmology, 65, 877-881.

Patti, J. C., and Cinotti, A. A. (1975). Iris photocoagulation therapy of aphakic pupillary block. Archives of Ophthalmology, 93, 347-348.

Shaffer, R. N. (1954). The role of the vitreous detachment in aphakic and malignant glaucoma. Transactions of the American Academy of Ophthalmology and Otolaryngology, 58, 217-231.

Smith, P. (1891). On the Pathology and Treatment of Glaucoma. J. \& A. Churchill: London.

Weeks, J. E. (1923). Glaucoma after cataract extraction. Transactions of the American Academy of Ophthalmology and Otolaryngology, 28, 162-173.

Weiss, D. I., and Shaffer, R. N. (1972). Ciliary block glaucoma. Transactions of the American Academy of Ophthalmology and Otolaryngology, 76, 450-460.

Wheeler, C. B. (1977). Laser iridectomy. Physiological and Medical Biology, 22, 1115-1135.

Wright, J. E. (1968). The role of the vitreous face following cataract extraction. Transactions of the Ophthalmological Societies of the United Kingdom, 78, 461-471. 